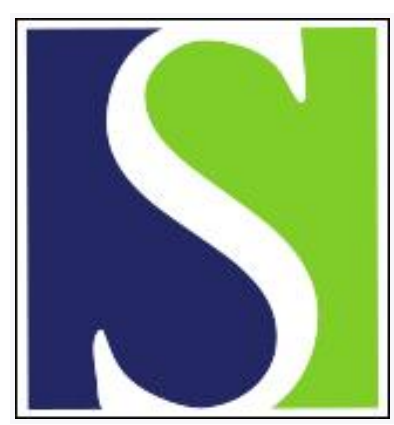

Scand J Work Environ Health 1992;18(6):393-399

https://doi.org/10.5271/sjweh.1565

Issue date: 01 Dec 1992

Prediction of silicosis and lung cancer in the Australian labor force exposed to silica.

by Nurminen M, Corvalan C, Leigh J, Baker G

Affiliation: Research and Scientific Division, National Institute of Occupational Health and Safety, Sydney, New South Wales, Australia.

This article in PubMed: www.ncbi.nlm.nih.gov/pubmed/1336621

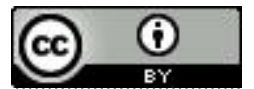




\title{
Prediction of silicosis and lung cancer in the Australian labor force exposed to silica
}

\author{
by Markku Nurminen, PhD, ${ }^{1,2}$ Carlos Corvalan, MA, ${ }^{1}$ James Leigh, MD, ${ }^{1}$ Gary Baker, $\mathrm{PhD}{ }^{1}$
}

\begin{abstract}
NURMINEN M, CORVALAN C, LEIGH J, BAKER G. Prediction of silicosis and lung cancer in the Australian labor force exposed to silica. Scand J Work Environ Health 1992;18:393-9. Empirical models for risk, based on recently published epidemiologic data, and simple prediction formulas were used to predict the occurrence of silicosis and lung cancer in the Australian labor force currently exposed to crystalline silica dust. As a result of an 0.9 (range 0.4-1.9)\% average lifetime risk, approximately 1010 (range 380-2410) silicosis cases were predicted for the next 40 years among the estimated 136400 men exposed at current silica dust levels $[0.01-0.8$ (average 0.094$) \mathrm{mg} \cdot \mathrm{m}^{-3}$ ]. Approximately 630 extra lung cancer cases $(95 \%$ confidence interval $120-1320)$ would appear with an average excess risk of 0.5 (interval $0.1-1.1) \%$, the proportion of silica-induced lung cancer cases being about $15 \%$. Currently $77 \%$ of the at-risk labor force is exposed to silica dust levels of $\leq 0.1 \mathrm{mg} \cdot \mathrm{m}^{-3}$. With this level as the limit, about 440 (range 140-1210) silicosis cases and 410 (interval 90-780) extra lung cancer cases would occur in $\mathbf{4 0}$ years. Adopting this level as the national exposure standard would reduce the risk of silicosis cases by $52 \%$ and the excess risk of lung cancer by $36 \%$.
\end{abstract}

Key terms: epidemiologic methods, hygienic standards, industry, lung diseases, miners, modeling, occupation, risk assessment, quartz.

Exposure to crystalline silica (silicon dioxide) dust is a worldwide occupational hazard causing disability and death among workers in industries such as mining, quarrying, glass making, and metal founding. Inhaled silica can accumulate in the body and cause diseases of the respiratory system and other organs (eg, the kidney). The biological effects of exposure to respirable silica can be modified by concomitant exposure to other minerals. Prolonged exposure to elevated levels of silica can cause an extensive build-up of fibrous tissue in the lung and result in restrictive lung disease (silicosis). More recently the question has arisen of whether silica and silicosis are related to the occurrence of lung. cancer.

Current knowledge of the potential carcinogenicity of silica dust has been summarized by the following three conclusions in a report by the International Agency for Research on Cancer (IARC) (1): "(i) silica is carcinogenic in experimental systems [2]; (ii) lung cancer risk is increased among workers exposed to silica and not exclusively among those exposed to known carcinogens; (iii) when investigated separately, the lung cancer risk is concentrated among the subpopulation of exposed workers who develop silicosis [ p 4]." Accordingly, IARC has classified silica as a probable human carcinogen, and this classification has been sup-

\footnotetext{
${ }^{1}$ Research and Scientific Division, National Institute of Occupational Health and Safety, Sydney, New South Wales, Australia.

2 Department of Epidemiology and Biostatistics, Institute of Occupational Health, Helsinki, Finland.
}

Reprint requests to: Dr M Nurminen, Department of Epidemiology and Biostatistics, Institute of Occupational Health, Topeliuksenkatu 41 a A, SF-00250 Helsinki, Finland. ported by the results of other epidemiologic studies [eg, that of Hnizdo \& Sluis-Cremer (3)], although the mechanism is still controversial.

Thus silica can cause occupational disease unless it is appropriately controlled. In the past, Australian control strategies have been designed to prevent the occurrence of silicosis. At those workplaces in which existing standards have been enforced by the inspectorate and modern control methods have been rigorously applied, there appears to be little evidence of adverse health outcomes, although the data may be incomplete. Problems may arise however where controls have not been applied. The various Australian standards, ranging from 0.15 to $0.2 \mathrm{mg} \cdot \mathrm{m}^{-3}$ depending on the state, are historically based on the occurrence of silicosis in Sydney sandstone workers.

An important component of control strategies involves the monitoring of respirable dust exposure. The current Australian collection method is based on British Medical Research Council criteria, which differ slightly in size collection, and hence mass concentration, from the criteria of the American Conference of Governmental Industrial Hygienists in the United States (ie, $0.1 \mathrm{mg} \cdot \mathrm{m}^{-3}$ ). International standards vary from 0.04 to $0.47 \mathrm{mg} \cdot \mathrm{m}^{-3}$ and reflect different measurement criteria, information bases, and standard setting procedures.

Australian data on the extent of silica exposure and health effects are limited. While some industries such as mining have good exposure monitoring records and compensation registers on silicosis, little information is available for industries such as manufacturing and construction. Therefore an approach to national risk assessment is needed to supplement existing monitoring and health effects data. 
The data on current health outcome are derived from compensation systems and reflect past exposure to silica. The largest numbers of workers compensated by the New South Wales (NSW) Dust Diseases Board come from the nonmining sector. The industrial breakdown for the 151 workers compensated for silicosis (ie, incidence rate of 13.7 per year) in 1980-1990 is as follows: $40 \%$ manufacturing, $41 \%$ construction, $13 \%$ mining, and $6 \%$ other industries.

Other health outcomes such as lung cancer or chronic obstructive airway disease have not been assessed for the labor force exposed to silica. However, specific studies on lung cancer and airway disease in Western Australia revealed that these diseases are more prevalent among silica-exposed workers than among the general population, but it was unclear whether their increased frequency was due to silica exposure, cigarette smoking, or the joint operation of the two.

The purpose of this study was to estimate the risks of silicosis and lung cancer associated with exposure to silica dust at the current concentration levels in Australia or, at most, at a level of $0.1 \mathrm{mg} \cdot \mathrm{m}^{-3}$. The risk estimates were then translated into predicted numbers of cases of these diseases to obtain an assessment of the magnitude and significance of the occupational health problem related to silica on a national level. The reported figures may also serve for international comparisons. Finally, the methods used for risk assessment may be of interest per se for possible application in similar situations elsewhere.

\section{Materials and methods}

\section{Exposed populations and exposure levels}

The labor force at risk of an untoward health effect due to silica exposure was first defined by identifying the occupations and industries with potential silica exposure according to the Australian Standard Classification of Occupations (ASCO) and the Austrialian Standard Industrial Classification (ASIC) of the Australian Bureau of Statistics. The sizes of the populations were the numbers of the industrial populations, estimated for the six states and The Northern Territories on the basis of data from the 1986 Census of Population and Housing (Australian Bureau of Statistics, unpublished tables). These estimates were then corrected for the actual numbers of people who would be exposed to silica dust in their work in a particular ASIC classification. Females were excluded because only a small number was considered exposed. Thus approximately 136400 male workers in the manufacturing (11\%), construction $(70 \%)$, and mining (19\%) industries were identified.

Current Australian legislation and standards are diverse, separate legislation applying to industrial sectors and states. Of the at-risk labor force, approximately $60 \%$ is in work with an exposure limit of $0.1 \mathrm{mg}$. $\mathrm{m}^{-3}$, for $6 \%$ the limit is $0.15 \mathrm{mg} \cdot \mathrm{m}^{-3}$, for $26 \%$ it is
$0.2 \mathrm{mg} \cdot \mathrm{m}^{-3}$, and for $8 \%$ the exposure level is unknown.

Actual median exposures to respirable silica were estimated for the at-risk labor force by constructing a $50 \times 20$ industry-by-occupation exposure matrix with the use of exposure data from industry and the work experience of the occupational hygienists in the $\mathrm{Na}$ tional Institute of Occupational Health and Safety (NIOHS) Expert Working Group on Crystalline Silica (Technical Report on Chrystalline Silica). In the 665 categories with a nonzero exposure intensity, the mean level was $0.094 \mathrm{mg} \cdot \mathrm{m}^{-3}$. Actually, $77 \%$ of the at-risk labor force was estimated to be currently exposed to concentrations of $\leq 0.1 \mathrm{mg} \cdot \mathrm{m}^{-3}$, whereas $90 \%$ was considered exposed to levels of $\leq 0.2$ $\mathrm{mg} \cdot \mathrm{m}^{-3}$.

The industries with median estimated exposures to respirable silica exceeding $0.2 \mathrm{mg} \cdot \mathrm{m}^{-3}$ came mainly from the following three sectors: manufacture of clay bricks (ASIC 2861), mining and exploration services (ASIC 1620), and earthmoving and dredging (ASIC 4248). In these industries, with an estimated 13770 workers, $84 \%$ of the work force is estimated to be exposed to silica at levels above $0.2 \mathrm{mg} \cdot \mathrm{m}^{-3}$, and for $93 \%$ exposure concentrations exceed $0.1 \mathrm{mg} \cdot \mathrm{m}^{-3}$. These industries are dominated by small companies and contractors, with the largest number of workers in the construction sector. Considering all industries, an estimated $13320(10 \%)$ workers are exposed to levels exceeding $0.2 \mathrm{mg} \cdot \mathrm{m}^{-3}$, and for $31572(23 \%)$ exposure is above $0.1 \mathrm{mg} \cdot \mathrm{m}^{-3}$.

The occupations with the highest median estimated exposures involved drilling plant operators (ASCO 7317), excavating and earthmoving plant operators (ASCO 7201), and clay- and stone-processing machine operators (ASCO 7419).

The distribution of the duration of exposure time - used in the modeling for risk - was roughly estimated from data on the employment histories of 13380 NSW coal miners in a cross-sectional survey conducted in 1985 by NIOHS. The average exposure times increased progressively from five years for the 20 - to 24-year-old active miners to a maximum of 25 years for the 75- to 79-year-old retired miners with an overall mean of 14 years.

\section{Risk modeling and prediction formulas}

The risk of developing a lung disease due to occupational exposure to dusts at various levels can be assessed by means of a model for exposure-effect relations. However, the concept of risk being a probability measure pertains to an individual. In epidemiology, risk can be estimated as a cumulative incidence rate in a population. The ratio of two risks (relative risk) expresses the relative magnitude of the risk at a given level of exposure to the corresponding magnitude at some other (reference) level, usually nonexposure. Risk functions describe the change in risk as a function of 
a change in an exposure index. The cumulative exposure index was formed as the product of the intensity and duration of exposure. Because we used median exposure intensities and average exposure durations, the cumulative index was presumably reasonable. These entities can be translated into the predicted number of disease cases caused by the exposure in question.

For silicosis the risk was quantitated by a model relating cumulative respirable silica exposure (particleyears) to the cumulative incidence rate. We assumed an exposure-effect relation in which the effect was proportional to a power of the exposure: $R_{a}=\alpha(L$. $\left.D_{a}\right)^{\beta}$, where $R_{a}$ stood for the risk in the $a^{\text {th }}$ age category, $\mathrm{L}$ was the dust level or intensity of exposure $\left(\mathrm{mg} \cdot \mathrm{m}^{-3}\right), \mathrm{D}_{\mathrm{a}}$ was the average attained duration of exposure (in years) for the subjects in the $a^{\text {th }}$ age category, and $\alpha$ and $\beta$ were the model form parameters to be estimated from the empirical data.

To estimate the parameters of the risk function, we used the experience of hard-rock (gold, uranium, and mixed) miners in Ontario, the relation between cumulative respirable silica exposure (lagged five years), and the risk of silicosis derived by Muir et al (4), who fitted Weibull models based on the radiographic readings of suspected silicosis by five different radiologists. We accepted an exposure-effect relation showing agreement between three or more readers as the best overall model (figure 8 in reference 4). The values used in the power function were estimated from the graph as $\hat{\alpha}=0.00109$ and $\hat{\beta}=1.72$. As an indication of the variability of the risk estimates, we chose the range of values indicated by the results of fitting two models for different levels of reader consensus, one in which all of the readers agreed on the diagnosis of silicosis [radiological category $\geq 1 / 1$ with round opacities, as defined by the International Labour Organisation (ILO) (5)] ( $\hat{\alpha}=0.00034$ and $\hat{\beta}=1.91)$ and another in which any reader made the diagnosis $(\hat{\alpha}=0.00309$ and $\hat{\beta}=1.54$ ).

The preceding risk model assumes, first, that silica dust is a necessary cause of silicosis. In other words, there is no risk $(R=0)$ if there is no cumulative exposure $(\mathrm{L}=0$ or $\mathrm{D}=0)$. Second, it is the accumulation of silica over the years, that is, the product of level and duration $(\mathrm{L} \cdot \mathrm{D})$, that determines the risk and not the intensity of exposure in itself. However, several additional assumptions are necessary to predict realizations of risks in terms of numbers of people sustained.

Suppose that a dynamic population is being followed. The industrial population has a turnover in membership as new employees enter the labor force and others retire, but the population profile is unchanging over time (stationary) with respect to its distribution of (i) size of age groups and (ii) duration of exposure. Suppose also that the age distribution is that of a general, employed male population, that the members of the population remain exposed to a constant intensity of silica dust while in a particular job, and that exposure ceases upon retirement, whereby the retired ex-workers are no longer at risk of silicosis progression. [This last assumption is almost certainly an unquantifiable underestimation of the risk.] Finally, the hypothetical period of follow-up is extended over 40 years, corresponding to the maximum duration of employment in a worker's life (of which, on the average, 14 years is spent in exposed work).

Thus, for example, we computed the silicosis risk at the start of a 40-year follow-up for a 20-year-old worker exposed throughout his employment in a particular industry or occupation to a constant level of silica dust as $R=(5$ years $) \Sigma_{a} R_{a} / D_{a}$, where the attained mean duration of exposure in the successive five-year age categories are $2.5,7.5, \ldots, 37.5$ years. An average worklife risk was then computed by averaging the risks of 665 individuals, one in each of the 665 industrial or occupational categories with a nonzero exposure intensity.

The expected number of silicosis cases (E) was thus computed as $\mathrm{E}=\mathrm{S} \cdot \mathrm{T} \cdot \mathrm{I}$, where $\mathrm{S}$ stood for the size of the industrial subpopulation, $T$ was the followup time, and I was the incidence rate of silicosis (in units of cases per year). This rate was considered a weighted average of the age-specific incidence densities, $I_{a}(a=20-24$ years, . ., 60-64 years); that is, $\mathrm{I}=\Sigma_{\mathrm{a}} \mathrm{W}_{\mathrm{a}} \mathrm{I}_{\mathrm{a}}$, where the weights were defined as $\mathrm{W}_{\mathrm{a}}=$ $\mathrm{N}_{\mathrm{a}} \mathrm{F}_{\mathrm{a}} / \Sigma_{\mathrm{a}} \mathrm{N}_{\mathrm{a}} \mathrm{F}_{\mathrm{a}}\left(\Sigma_{\mathrm{a}} \mathrm{W}_{\mathrm{a}}=1\right)$. Here $\mathrm{N}_{\mathrm{a}}$ was the number of the male resident population of New South Wales on 30 June 1986 in the $a^{\text {th }}$ age category, and $F_{a}$ was the fraction of the corresponding population employed in $1989-1990$. $I_{2}$ was solved from the relation between incidence density and cumulative incidence rate, which was used as an estimate for risk; specifically, $\mathbf{R}_{\mathrm{a}}=$ 1-exp $\left(-I_{a} D_{a}\right)$. But, since the silicosis risks were small, an accurate approximation was $\mathrm{I}_{\mathrm{a}}=\mathrm{R}_{\mathrm{a}} / \mathrm{D}_{\mathrm{a}}$. The total expected number of silicosis cases was then obtained by summing over the 665 industrial or occupational subpopulations associated with a nonzero exposure intensity.

In the case of cancer of the bronchus, trachea and lung, the risk was assessed in terms of excess numbers over the age-specific incidences among NSW male residents in 1984 on the basis of the statistics of the NSW Central Cancer Registry (Coates, personal communication). The result was $0.0,0.4,3.2,3.4,12.6,37.6$, $94.3,150.9,268.9,361.1,409.1,540.9,522.1$ per 100000 for age groups $20-24,25-29,30-34$, $35-39,40-44,45-49,50-54,55-59,60-64$, $65-69,70-74,75-79$, and $\geq 80$ years, respectively.

The gradient in the risk ratio (RR) for a unit increase of $10^{3}$ particle-years $(\mathrm{Y})$, standardized for smoking, year of birth and age, was estimated from the South African gold miner material by a proportional hazards model (3) as $R R=1.023^{\mathrm{Y}}$. In these data, the combined effect of dust and smoking was more than additive, and it was assumed to be multiplicative so that the proportionality of hazards would apply. The $95 \%$ confidence limits for RR, again based on the gold 
miner data, were computed as $1.005^{\mathrm{Y}}$ (lower limit) and $1.042^{\mathrm{Y}}$ (upper limit).

The particle-years were converted from the median dust level $(\mathrm{L})$, in units of $10^{3} \mathrm{mg} \cdot \mathrm{m}^{-3}$, and the average duration of exposure in the $a^{\text {th }}$ age category $\left(D_{a}\right)$, in years, according to the equation $Y_{a}=3385\left(L \cdot D_{a}\right)$. Ninety-five side-by-side measurements of particle counts for respirable surface area and respiratory gravimetric quartz were obtained from the South African National Centre for Occupational Health (Rendall, personal communication), and a conversion equation, $1 \mathrm{mg} \cdot \mathrm{m}^{-3}$ respirable quartz-years $=3385$ respirable surface area particle-years, was derived.

There are several assumptions germane to the preceding risk ratio model for lung cancer. First, the reference level of $R R=1$ is attained with $Y=0$ in the preceding risk function. Incidentally, the reference level actually used in the gold miner study was the lowest exposure category with $Y=7-15$, whereas the highest exposure was $Y=80$. Second, an increase in $R R$ by a given intensity of exposure (dust level) is proportional to (average) duration of exposure and vice versa. Third, the RR increases monotonically with exposure at a constant level and remains constant after the cessation of exposure.

The demographic model for lung cancer incidence also assumed the age structure (ranging from 20 to 64 years) of an employed male population. In addition, the retired (aged 65 to $\geq 80$ years) workers formerly exposed to silica were included in the analysis. As with silicosis, the hypothetical follow-up period for the incidence of lung cancer was considered to extend for 40 years.

Thus, for example, the excess risk of lung cancer due to silica dust for a 20-year-old man exposed throughout a maximum work period of 40 years in a particular industry or occupation is $R=(5$ years $)$ $\Sigma_{\mathrm{a}}\left(R R_{\mathrm{a}}-1\right) \mathrm{I}_{\mathrm{a}}$ if the summation and the $\mathrm{D}_{\mathrm{a}}$ are defined as in the preceding estimation for silicosis.

The excess number $(E)$ of cancer cases was thus computed as $\mathrm{E}=\mathrm{S} \cdot \mathrm{T} \Sigma_{\mathrm{a}}\left(\mathrm{RR}_{\mathrm{a}}-1\right) \mathrm{W}_{\mathrm{a}} \mathrm{I}_{\mathrm{a}}$, where $\mathrm{I}_{\mathrm{a}}$ was the five-year age-specific incidence of lung cancer and the summation was from 20 years onwards. Note that, if $R R=1$, then $E=0$. The total excess number was then obtained by a tally of the cases in the 665 industrial or occupational subpopulations with a nonzero exposure level.

\section{Results}

Tables 1 and 2 show the average life-long risk of silicosis for an individual exposed to silica and the expected numbers of silicosis in the exposed population separately for the currently prevailing exposure levels and for the lower control limits, while tables 3 and 4 give the corresponding average worklife risks and excess numbers of lung cancer.

\section{Effects anticipated with current hygienic standards}

At the current exposure levels for quartz in Australian workplaces the risk model predicted a life-long risk of
Table 1. Average risk of silicosis for 665 hypothetical men employed from age 20 to 60 years, one each in the 665 industrial or occupational categories with a nonzero exposure intensity. Predicted risks are given separately for the currently prevailing exposure leveis and for exposure levels up to 0.1 and $0.2 \mathrm{mg} \cdot \mathrm{m}^{-3}$. Also shown is the range of the predictions according to diagnostic variability.

\begin{tabular}{lcc}
\hline Exposure level & $\begin{array}{c}\text { Estimated risk } \\
(\%)\end{array}$ & $\begin{array}{c}\text { Diagnostic range } \\
(\%)\end{array}$ \\
\hline Current & 0.87 & $0.35-1.9$ \\
$\leq 0.2 \mathrm{mg} \cdot \mathrm{m}^{-3}$ & 0.74 & $0.29-1.7$ \\
$\leq 0.1 \mathrm{mg} \cdot \mathrm{m}^{-3}$ & 0.41 & $0.14-1.0$ \\
\hline
\end{tabular}

Table 2. Expected numbers of silicosis cases in a dynamic population of 136433 men exposed to silica in a 40 -year followup period. The population was assumed to be stationary with respect to duration of exposure and age distribution. Predicted numbers are given separately for the currently prevailing exposure levels and for exposure levels up to 0.1 and 0.2 $\mathrm{mg} \cdot \mathrm{m}^{-3}$. Also shown is the range of the predictions according to diagnostic variability.

\begin{tabular}{lcc}
\hline Exposure level & $\begin{array}{c}\text { Estimated } \\
\text { number }\end{array}$ & Diagnostic range \\
\hline Current & 1010 & $380-2410$ \\
$\leq 0.2 \mathrm{mg} \cdot \mathrm{m}^{-3}$ & 780 & $280-1970$ \\
$\leq 0.1 \mathrm{mg} \cdot \mathrm{m}^{-3}$ & 440 & $140-1270$ \\
\hline
\end{tabular}

Table 3. Average risk of lung cancer for 665 hypothetical men employed from age 20 to 60 years, one each in the 665 industrial or occupational categories with a nonzero exposure intensity. The predicted numbers and their associated $95 \%$ confidence intervals are given separately for the currently prevailing exposure levels and for exposure levels up to 0.1 and 0.2 $\mathrm{mg} \cdot \mathrm{m}^{-3}$

\begin{tabular}{lcc}
\hline Exposure level & $\begin{array}{c}\text { Estimated risk } \\
(\%)\end{array}$ & $\begin{array}{c}95 \% \text { confidence } \\
\text { interval } \\
(\%)\end{array}$ \\
\hline Current & 0.47 & $0.08-1.10$ \\
$\leq 0.2 \mathrm{mg} \cdot \mathrm{m}^{-3}$ & 0.42 & $0.08-0.90$ \\
$\leq 0.1 \mathrm{mg} \cdot \mathrm{m}^{-3}$ & 0.30 & $0.06-0.59$ \\
\hline
\end{tabular}

Table 4. Excess numbers of lung cancer cases in a dynamic population of 136400 men exposed to silica in a 40 -year followup period. The population was assumed to be stationary with respect to duration of exposure and age distribution. The predicted numbers and their associated $95 \%$ confidence intervals are given separately for the currently prevailing exposure levels and for exposure levels up to 0.1 and 0.2 $\mathrm{mg} \cdot \mathrm{m}^{-3}$.

\begin{tabular}{lcc}
\hline Exposure level & $\begin{array}{c}\text { Estimated } \\
\text { number }\end{array}$ & $\begin{array}{c}95 \% \text { confidence } \\
\text { interval }\end{array}$ \\
\hline Current & 630 & $120-1320$ \\
$\leq 0.2 \mathrm{mg} \cdot \mathrm{m}^{-3}$ & 550 & $110-1090$ \\
$\leq 0.1 \mathrm{mg} \cdot \mathrm{m}^{-3}$ & 410 & $90-780$ \\
\hline
\end{tabular}


$0.9 \%$ for silicosis averaged over the industrial or occupational categories. The model further predicted that over 1000 cases of silicosis would be observed in a dynamic population of 136400 exposed workers in the subsequent 40 years.

For lung cancer the risk ratio model predicted that, if the current quartz exposure levels prevailed, a worklife excess risk of $0.5 \%$ would operate, averaging across the job-exposure matrix. Consequently, approximately 630 excess cases were predicted in addition to those cancers which would occur due to life-style and general environmental risk factors (approximately 3600). Thus the proportion of work-related lung cancers of all lung cancers in the exposed population would be $15(95 \%$ confidence interval $4-27) \%$.

Of the incident cases of lung cancer due to silica exposure, about $20 \%$ would occur before the age of 60 years, $37 \%$ between 60 and 70 years of age, $33 \%$ between 70 and 80 years of age, and $10 \%$ after the age of 80 years.

\section{Effects anticipated with recommended hygienic standards}

When the exposure standard of $0.2 \mathrm{mg} \cdot \mathrm{m}^{-3}$ was applied to the same population follow-up, the model projection was for approximately 780 incident cases of silicosis with an average working lifetime risk of $0.7 \%$ (ie, a $15 \%$ reduction). If however an exposure standard of $0.1 \mathrm{mg} \cdot \mathrm{m}^{-3}$ were to be implemented, and actual exposures would not exceed this level, only 440 cases of silicosis would be expected with an average risk of $0.4 \%$ (ie, a $52 \%$ reduction).

If, for lung cancer, an exposure level of 0.2 $\mathrm{mg} \cdot \mathrm{m}^{-3}$ was the standard adhered to, then the excess number of cancer cases would be 550 as the result of an average excess risk of $0.4 \%$ (ie, a $12 \%$ reduction). Alternatively, if the exposure standard was set at $0.1 \mathrm{mg} \cdot \mathrm{m}^{-3}$, the excess number of lung cancer cases would be about 410 , the average excess risk being $0.3 \%$ (ie, a $36 \%$ reduction).

\section{Effects anticipated with maximal exposure duration}

The maximal impact of silica dust can be estimated by considering a 40 -year exposure period for all workers. For silicosis the expected numbers of table 2 would be increased by $19 \%$. Thus, at the current exposure levels, 1210 (range 490-2700) cases would be observed.

Regarding lung cancer, the figures of table 4 would be doubled because of the many incident cases among the retired miners. At the current levels, an excess of 1380 (interval 230-3880) cases was predicted.

\section{Discussion}

A crucial constituent in any attempt to estimate the quantitative effect of exposure to a given amount of silica dust is the reliability of the method assessing the current level of exposure in the various industries and occupations. The members of the NIOHS Expert Working Group on Crystalline Silica used their expertise of the conditions and processes at the work sites and supplementary information from companies, where available, to evaluate the median level of exposure in the occupational subpopulations and the number of workers actually exposed to silica. Yet, owing to their crude nature, these data have to be examined with reservation.

An investigation among miners in the British coal mining industry provided evidence to the effect that gravimetric measurements of cumulative respirable quartz is a better exposure measure of health risk than cumulative konimeter counts. (See reference 4.) In the present study, conversion data of 95 side-by-side thermal precipitator counts and gravimetric silica measurements were available with which to estimate the risk of lung cancer on the basis of data on South African gold miners. The applied conversion factor is consistent with the one derived indirectly from a larger series of 650 parallel measurements reported earlier for South African gold miners $(6,7,8)$.

In estimating exposure-effect relations for chronic lung diseases, we were faced with many methodological difficulties. The problems included, for example, how to account for duration of exposure, age at first exposure, and time since the start of exposure. In the case of lung cancer, there is the confounding or modifying effect of smoking, which was evaluated by Hnizdo \& Sluis-Cremer (3) using the general relative risk model of Breslow \& Storer (9). For silicosis the diagnostic variability complicates the analysis. Despite these problems we felt that it would be useful to construct a model to predict the expected number of silicosis cases and the expected number of excess cancer cases and to provide estimates of the associated risks.

In the risk modeling, we used a cumulative index of the exposure, which was a product of the median level and average duration of individual worker experiences in the particular industry or occupation or age categories. This approach, which was also used in Canadian (4) and Chinese (10) studies on silicosis, was followed because, in general, it is the implicitly adopted strategy for dust control measures. However, the use of such an index implies, for example, that the increase in the relative risk of lung cancer risk caused by exposure to, say, a silica dust level of $0.1 \mathrm{mg} \cdot \mathrm{m}^{-3}$ for 40 years is the same as that caused by exposure to a level of $0.4 \mathrm{mg} \cdot \mathrm{m}^{-3}$ for 10 years. However, we used the model only to provide estimates of life-long risks, that is, for a fixed duration of 40 years of follow-up at exposures to median levels within the specific age categories. Given these constraints, we thus assumed that the increase in risk was exponentially proportional to the intensity (dust level) of silica exposure.

Time since first exposure is a factor influencing lung cancer incidence. No increased risk is probably 
produced for five years' exposure, even if the level of exposure is very high. However, the induction period is, by and large, a nonissue in the prediction of longterm risks, as the probability of the inception of lung cancer during the first five or ten years after first exposure is generally low.

On the other hand, the last five years of exposure before the detection of cancer should not be counted as contributing to the exposure index. In effect, this lag time was taken into account in the analysis of the gold miner data, as the miners had an average of 24 years of underground exposure and the average duration of exposure after the start of follow-up - the cumulated exposures were considered only to this point in time - was 3.3 years (3).

In the modeling for the risk of silicosis, a five-year lagging of exposures was explicitly incorporated into the analysis (4). Thus the time between the deposition of silica in the lungs and the clinical appearance of silicosis was taken into account when the expected numbers of cases were computed.

The epidemiologic relation between silicosis (ILO category $\geq 1 / 1$ with round opacities) in Ontario hardrock miners and cumulative exposure to silica (free crystalline silica $-\alpha$ quartz) estimated by Muir et al (4), may not be directly applicable to conditions of Australian industrial work sites. The Canadian study cautioned of possible confounding by coexposures when risks due to silica dust in one industry or occupation are compared with those reported in other contexts. For example, some forms of crystalline silica, such as cristobalite and tridymite, may have a greater fibrogenic potential than silica itself. On the other hand, silica mixed with high concentrations of inert coal dust and silicates may diminish the apparent toxicity of the silica fraction. Similarly, high concentrations of clay minerals in silica dust may reduce the risk of silicosis among workers in the brick industry.

The lung cancer predictions rest on the premise that silica dust is indeed carcinogenic in humans. The evidence to support this hypothesis is limited due to deficiencies in many of the studies conducted thus far. Nevertheless, the exposure-effect relation established recently from the South African gold miner experience is on a sound scientific basis and thus serves the purposes of risk analysis.

The applicability of the relative risk model derived for lung cancer by Hnizdo \& Sluis-Cremer (3) to Australian circumstances can also be doubted. The concentrations of respirable silica considered representative of the mining industry in South Africa range from 0.05 to $0.84 \mathrm{mg} \cdot \mathrm{m}^{-3}$ for underground dust. In the Australian industries the exposure levels are estimated to be similar, varying from 0.01 to $0.8 \mathrm{mg} \cdot \mathrm{m}^{-3}$. We had to presume however that the smoking habits of the two populations were similar and that the coexposures prevalent in South African gold mines, such as any possible differential exposure to radon daughters and diesel fumes, did not confound the established relation between silica dust exposure and lung cancer risk.

Our demographic population model implied a simple prediction formula. The underlying assumption was that the distributions of age and duration of exposure remained unchanged over time in the followed populations. An alternative model would be a cohort followup. However, a dynamic population with natural turnover in membership has stationary age and exposure distributions. This is a more realistic model with which to describe the entire labor force than a closed employed population that is inherently variable. For example, whereas an occupational cohort ages and is depleted during the course of follow-up, dynamic population experience can be increased at will by an extension of follow-up. In practice, long-term followup of a cohort defined at various times within the risk period of interest leads to a less informative study base than dynamic population coverage, provided that information on exposure is equally accessible in either situation.

The methods used for risk estimation unavoidably gave very approximate projections because they involved a myriad of assumptions whose tenability could not be verified with certainty. Therefore the presentation of mere point estimates of the expected and excess numbers would undoubtedly give a misleading impression of precision. Morris (11) has stated this position more firmly: "Providing decisionmakers estimates of environmental cancer risks without corresponding estimates of the associated uncertainty is irresponsible [p 329]." Confidence intervals and diagnostic ranges were computed for the risk parameters (and thereby for the numbers of lung diseases) to provide some idea of the variability of the estimation. But possible model mispecifications could well have overridden the sampling or diagnostic errors.

It has to be recognized, too, that the retrospective empirical data on which the risk models were based were few, being 32 cases of silicosis among 2109 hardrock miners in Ontario (4) and, in all, 77 cases of lung cancer among 2209 gold miners in South Africa (3). Thus the resulting error bounds for the numbers of lung diseases were wide. To this variability we should add the uncertainty associated with the estimates of the level of exposure, which were treated as nonrandom quantities in the analysis.

The comparison of the risk estimates estimated from the present study with those obtained from other countries is difficult because of different exposure conditions, a different duration of exposure or follow-up, and the different prediction models used. Nevertheless, a recent study on silicosis conducted in a tungsten mine in China (10), where the respirable silica dust concentrations ranged approximately from 0.25 to $2.5 \mathrm{mg} \cdot \mathrm{m}^{-3}$, estimated that, if the sensitivity of diagnosis is $95 \%$, an exposure limit of $0.24 \mathrm{mg} \cdot \mathrm{m}^{-3}$ for a duration of exposure of 30 years (taking the duration of employment in a worker's life as 30 to 
40 years) corresponds to a probability of silicosis of $0.8 \%$. In the present study, the estimated median exposures varied from 0.01 to $0.8 \mathrm{mg} \cdot \mathrm{m}^{-3}$ (average $0.094 \mathrm{mg} \cdot \mathrm{m}^{-3}$ ), and an exposure of $0.2 \mathrm{mg} \cdot \mathrm{m}^{-3}$ for the average duration of 14 years' exposure (maximum 25 years) produced a life-long risk of silicosis of $0.87 \%$. Thus the two estimates were of the same order of magnitude.

There has been considerable interest in the proportion of lung cancers caused by occupational exposures. While the silica-induced cases represent only a minute proportion of the annual incidence in the general male population, they nevertheless constitute $15 \%$ of the case load among the silica-exposed work force.

Insofar as a research group is allowed to participate in the discussion involved in the setting of hygienic standards for work environment exposures, some concluding remarks are in order. First, control measures should be designed that consider the occurrence of both silicosis and lung cancer, as a necropsy study found no association between lung cancer and silicosis of the lung, or silicosis of the pleura (3). Second, in developing strategies for lung disease prevention, the primary consideration should be the median level of silica exposure in an industry. A secondary concern is then the distribution of dust exposure according to occupational class within the industry. Close study of the industry-by-occupation exposure matrix led to the incontrovertible conclusion that urgent attention should be paid to the work conditions of certain occupations in all industries. For example, in each industry with drilling plant operators, this occupation was the one with the highest exposures. The immediate need for improved hygiene is clear without any of the predictions of this paper.

\section{Acknowledgments}

This research was based on at-risk population and silica exposure data provided kindly by the NIOHS Expert Working Group (Technical Report on Crystalline Silica). The authors would also like to acknowledge the assistance of Ms K O'Flynn, Ms J Plimsoll, and Mr S Weeden.

\section{References}

1. Simonato L, Saracci R. Epidemiological aspects of the relationship between exposure to silica dust and lung cancer. In: Simonato L, Fletcher AC, Saracci R, Thomas TL, ed. Occupational exposure to silica and cancer risk. Lyon: International Agency for Research on Cancer, 1990. (IARC scientific publications; no 97.)

2. International Agency for Research on Cancer (IARC). Silica and some silicates. Lyon: IARC, 1987. (IARC monographs on the evaluation of carcinogenic risk of chemicals to humans; vol 42.)

3. Hnizdo E, Sluis-Cremer GK. Silica exposure, silicosis, and lung cancer: a mortality study of South African gold miners. Br J Ind Med 1991;48:53-60.

4. Muir DCF, Julian JA, Shannon HS, Verma DK, Sebestyen A, Bernholz CD. Silica exposure and silicosis among Ontario hardrock miners: III. analysis and risk estimates. Am J Ind Med 1989;16:29-43.

5. International Labor Office (ILO). Guidelines for the use of ILO International Classification of Radiographs of Pneumoconioses. Revised edition. Geneva: ILO, 1980. (Occupational safety and health services; no 22 (rev).)

6. Beadle DG, Bradley AA. The composition of airborne dust in South African gold miners. In: Shapiro HA, ed. Pneumoconiosis (proceeding of the international conference, Johannesburg 1969). Capetown: Oxford University Press, 1970:462-66.

7. Wiles FJ, Faure MH. Chronic obstructive lung disease in gold miners. In: Walton WH, ed. Inhaled particles; vol IV (part 1). Oxford: Pergamon,1977:727-35.

8. Beadle DG. The relationship between the amount of dust breathed and the development of radiological signs of silicosis: an epidemiological study in South African gold miners. In: Walton WH, ed. Inhaled particles; vol III (part 1). Old Waking: Unwin, 1971:953-66.

9. Breslow NE, Storer BE. General relative risk functions for case-control studies. Am J Epidemiol 1985;122: 149-62.

10. Pang D, Fu S, Yang GC. Relation between exposure to respirable silica dust and silicosis in a tungsten mine in China. Br J Ind Med 1992;49:38-40.

11. Morris SC. Cancer risk assessment: a quantitative approach. New York, NY: Marcel Dekker, Inc, 1990.

Received for publication: 24 April 1992 